\title{
Interannual variability of the midsummer drought in Central America and the connection with sea surface temperatures
}

\author{
Tito Maldonado ${ }^{1,2,4}$, Anna Rutgersson ${ }^{2}$, Eric Alfaro ${ }^{3,4,5}$ Jorge Amador $^{3,4}$, and Björn Claremar ${ }^{2}$ \\ ${ }^{1}$ Centre for Natural Disaster Science, Uppsala University, Villav. 16, 752 36, Uppsala, Sweden \\ ${ }^{2}$ Department of Earth Sciences, Uppsala University, Villav. 16752 36, Uppsala, Sweden \\ ${ }^{3}$ School of Physics, University of Costa Rica, San Pedro de Montes de Oca, 11501-2060 San Jose, Costa Rica \\ ${ }^{4}$ Center for Geophysical Research, University of Costa Rica, San Pedro de Montes de Oca, 11501-2060 San Jose, Costa Rica \\ ${ }^{5}$ Centre for Research in Marine Sciences and Limnology, University of Costa Rica, San Pedro de Montes de Oca, \\ 11501-2060 San Jose, Costa Rica
}

Correspondence to: Tito Maldonado (tito.maldonado@geo.uu.se)

Received: 7 September 2015 - Revised: 7 April 2016 - Accepted: 18 April 2016 - Published: 26 April 2016

\begin{abstract}
The midsummer drought (MSD) in Central America is characterised in order to create annual indexes representing the timing of its phases (start, minimum and end), and other features relevant for MSD forecasting such as the intensity and the magnitude. The MSD intensity is defined as the minimum rainfall detected during the MSD, meanwhile the magnitude is the total precipitation divided by the total days between the start and end of the MSD. It is shown that the MSD extends along the Pacific coast, however, a similar MSD structure was detected also in two stations in the Caribbean side of Central America, located in Nicaragua. The MSD intensity and magnitude show a negative relationship with Niño 3.4 and a positive relationship with the Caribbean low-level jet (CLLJ) index, however for the Caribbean stations the results were not statistically significant, which is indicating that other processes might be modulating the precipitation during the MSD over the Caribbean coast. On the other hand, the temporal variables (start, minimum and end) show low and no significant correlations with the same indexes.

The results from canonical correlation analysis (CCA) show good performance to study the MSD intensity and magnitude, however, for the temporal indexes the performance is not satisfactory due to the low skill to predict the MSD phases. Moreover, we find that CCA shows potential predictability of the MSD intensity and magnitude using sea surface temperatures (SST) with leading times of up to 3 months. Using CCA as diagnostic tool it is found that during June, an SST dipole pattern upon the neighbouring waters to
\end{abstract}

Central America is the main variability mode controlling the inter-annual variability of the MSD features. However, there is also evidence that the regional waters are playing an important role in the annual modulation of the MSD features. The waters in the PDO vicinity might be also controlling the rainfall during the MSD, however, exerting an opposite effect at the north and south regions of Central America.

\section{Introduction}

The geographical features of Central America imprint the characteristics of the regional climate and weather at the isthmus. The region is conformed by a large and high mountain system surrounded by the Pacific and Atlantic oceans, which induces the maritime climate conditions governing in the region (Taylor and Alfaro, 2005). The interaction between the easterly winds (trades), which in turns are the dominant wind regime, and topography divide the region into two different climate areas: the Pacific located leeward of the main wind and the Caribbean presenting windward conditions.

The annual rainfall cycle for the entire region has already been well documented for Central America (Alfaro, 2002), and for the Eastern Tropical Pacific (ETP, Magaña et al., 1999; Amador et al., 2006). In the Pacific region the annual precipitation cycle exhibits a bimodal behaviour (Magaña et al., 1999; Taylor and Alfaro, 2005; Amador et al., 2006). The first precipitation maximum occurs during MayJune when the nearby ocean waters have warmed to around 
$29^{\circ} \mathrm{C}$ over the eastern Pacific warm pool, and the easterly winds have decreased, enhancing convection in the region. During July-August a relative precipitation minimum is observed, along with a decrease in the sea surface temperatures (SSTs) over the eastern Pacific warm pool, and an increase of the easterly winds. This reduction in the rainfall is known as the midsummer drought (MSD, Magaña et al., 1999; Amador et al., 2006). The second precipitation maximum occurs during August-September-October (ASO) and is accompanied by a reduction of the trades and a relative increase of the SSTs up to $28.5^{\circ} \mathrm{C}$ over the eastern Pacific warm pool. It is also during this quarter of the year that the hurricane season is more active in the Tropical North Atlantic (Amador et al., 2006).

On the other side, upon the Caribbean coast of Central America the annual precipitation cycle contrasts the one in the Pacific mainly during the boreal winter months, when wetter and more humid conditions are found over the eastern coast of Central America (Taylor and Alfaro, 2005; Amador et al., 2006). A similar bimodal cycle, however, has been extensively reported over the Greater Antilles (Chen and Taylor, 2002; Taylor et al., 2002; Spence et al., 2004; Ashby et al., 2005). The reduction in rainfall experienced during the summer months over the western Caribbean is argued to have a similar pattern to that in the Pacific (Martin and Schumacher, 2011). Little is known about the origins of the MSD in both, the Pacific and Caribbean. The processes involved in such rainfall decrease are most probably different to those operating in the western Central America and Mexico, however, both MSDs appear to share the Caribbean low-level jet (CLLJ) as main process increasing the moisture flux in the Caribbean, which suppresses convection and decreases rainfall (Magaña et al., 1999; Wang, 2007; Muñoz et al., 2008; Amador, 2008; Whyte et al., 2008). In this study, we focus on the variability of the MSD in the Pacific, nevertheless, we also examine two stations in the Caribbean side, to contrast the features present in both MSDs.

The development of the MSD has been explained in terms of the interaction of changes in the divergent (convergent) low-level winds over the warm waters nearby Mexico and Central America (Magaña et al., 1999). Recent studies such as Karnauskas et al. (2013) and Herrera et al. (2015) have proposed different hypothesis about the origin of the MSD. Karnauskas et al. (2013) argue that the MSD originates as a response to one single precipitation-enhancing mechanism occurring twice, contrary to a suppressing mechanism. The latitudinal dependence in the two peaks of precipitation surge as response to the biannual crossing of the solar declination, which leads to the two peaks in convective instability and hence rainfall. This hypothesis, nevertheless, does not explain the almost simultaneous occurrence of the MSD in both southern Mexico and Central America (Magaña et al., 1999). On the other hand, Herrera et al. (2015) describe the origins of the MSD studying the air-sea interaction between the CLLJ (Amador, 1998, 2008; Muñoz et al., 2008; Maldon- ado et al., 2016) and the ocean waters in the neighbourhood of the Pacific coast. Their findings show that the CLLJ peaks in July, provokes a cooling of the SSTs over the Pacific and a westward shift of low-level moisture convergence that combined with subsidence produce the MSD.

The MSD is important for the region since it develops mostly every year (see Fig. 4 in Magaña et al., 1999) in areas with high industrial and agricultural activities, which in turn, are highly populated (Alfaro, 2014). Most of the population lives in the Central American Pacific slope. Although the MSD is present almost every year, it shows high variability in space and time (Amador, 2008; Alfaro, 2014), and the understanding of this variability is still a scientific challenge (Amador et al., 2006; Amador, 2008; Herrera et al., 2015). The beginning, and duration are uncertainty factors for different socio-economic sectors such as the agricultural and potable water supply. On the other hand, one can expect that extreme MSD events impact negatively reducing the water resources in zones with such characteristics (Hernández and Fernández, 2015; Alfaro, 2014; Solano, 2015).

A better understanding of the variability of the MSD would then contribute to the knowledge about the weather and climate dynamics in the region, also to the information given to the economic and social sectors. Water resources, agriculture, and hydro-electrical power production are benefited in terms of obtaining better data for planning, mitigation and prevention to severe dry conditions, e.g. the droughts reported in the North Pacific region of Costa Rica during July 2014 (Chinchilla-Ramírez, 2014).

Previous studies have analysed the influence of the SST anomalies in the precipitation regime in Central America. Enfield and Alfaro (1999) have shown that the magnitude of the precipitation during the rainy season (from May to October) in Central America is highly modulated by the SST anomalies at both oceans. Alfaro (2007) and Fallas-López and Alfaro (2012b) studied the predictability of the rainfall using canonical correlation analysis (CCA) with SST as predictor. Both studies found that the SST modify the response on precipitation in different ways during each maximum, the first rainfall peak being modulated mainly by the SST over the tropical Atlantic, and the secondary maximum being controlled by a dipole in the SST anomalies over the neighbour oceans to the Central American coast. Moreover, FallasLópez and Alfaro (2012a) found that the MSD intensity is dependent on several global climate indexes such as the Atlantic Multi-Decadal Oscillation (AMO), Niño 3 (N3), and Pacific Decadal Oscillation (PDO). Maldonado and Alfaro (2011) and Maldonado et al. (2013) utilised CCA to explore the distribution of precipitation extreme events during the second precipitation maximum finding that during the second rainfall maximum, the total precipitation and temporal distribution of precipitation events are controlled by a dipole in the SSTs between the Pacific and the Caribbean-North Atlantic waters. Given the above evidence, it would be expected that SST is involved in the MSD variability at inter-annual scales. 
In fact, Alfaro (2014) found that warm (cool) conditions of Niño 3.4 tend to be associated to drier (wetter) MSD events in some regions of the North Pacific and Central Valley of Costa Rica.

Other climate processes occur simultaneously with the MSD, and could also alter the precipitation during JuneAugust (JJA) e.g the intensification of the North Atlantic Sub-tropical High (NASH, Wang, 2007), the Western Hemisphere Warm Pools (WHWM, Wang and Enfield, 2001, 2003), the North American Monsoon (Vera et al., 2006) and the CLLJ (Amador, 1998, 2008). Recently, Hidalgo et al. (2015) also found that the latitudinal position of the precipitation centre of mass is correlated with the intensity of the CLLJ, i.e a weaker (stronger) jet is associated to the northward (southward) shift of the latitudinal precipitation centre of mass, resulting in rainfall above normal during JJA that might be also associated with variations of the MSD events.

With that said, the targets of this study are first to contribute to the understanding of the climate in the region, and second to provide a systematic method for MSD forecasting. This study consists of an analysis of the connection between the features of the MSD observed in the Pacific and Caribbean coast of Central America and the anomalies in the SST of the regional waters by means of a combination of principal component analysis (PCA) and canonical correlation analysis (CCA). The precipitation observations, however, are first examined in order to determine the data quality and to characterised the MSD per station. The MSD is described in terms of start, timing, end, duration, depth (intensity) and total precipitation (magnitude). This representation is also used to produce annual indexes of those variables. Previous reports have already characterised the existence of the MSD in Costa Rica (Ramírez, 1983; Hernández and Fernández, 2015; Alfaro, 2014; Solano, 2015), nonetheless, in this study the portray is expanded to include the entire the region.

This manuscript is organised as follows: in Sect. 2 is described all the information relevant to the databases used in this study. Section 3 is a explanation of the methodology applied in this analysis. In Sect. 4 the result and Sect. 5 the discussion and concluding remarks are presented.

\section{Data}

A total of 25 gauge stations with daily observations of precipitation provided by the meteorological services in Central America are used. Their location is shown in Fig. 1, and the information about the coordinates of each station is given in Table 1 . The average annual cycle of precipitation for the selected period in every station is shown in Fig. 2. The MSD signal is noticeable in all the stations, around julian day 200 (July-August), except for Bluefields and Puerto Cabezas stations (in the Caribbean), where the rainfall reduction is observed near the julian day 300 (August-September). Note that the majority (23) of the stations are situated along the Pacific coast with only two stations located along the Caribbean

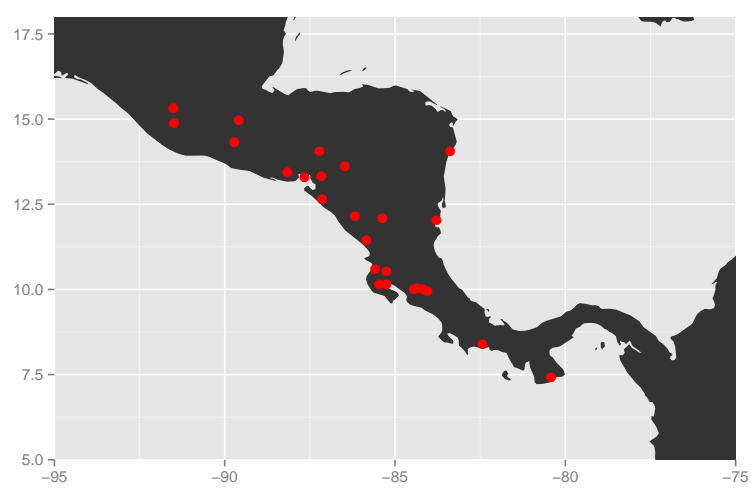

Figure 1. Spatial distribution of the gauge stations in Central America.

coast. The two Caribbean stations possess relevant features to describe the precipitation behaviour in the Caribbean slope, such as their location at the CLLJ exit and their contrasting annual precipitation cycle to that in the Pacific. Thus, in order to achieve a better representation of the complete region, we consider the Caribbean stations for the analysis. Since each meteorological station has a distinct time coverage, a common time series length is determined according to the percentage of missing data, and in this case, we pick a period in which stations do not surpass the $40 \%$ of missing data. Therefore, the selected time series length covers from 1961 to 2012, ensuring that each station posses at least $60 \%$ of the data. The gaps in the time series are filled using the methodology described in Alfaro and Soley (2009), which uses autoregressive models of order 1 . This method can filter persistent signals comparable to the length of the filter, and the estimated values are consistent with the statistical properties of the time series without external superposition of the data.

The extended reconstructed sea surface temperatures (ERSSTv3b, Xue et al., 2003; Smith et al., 2007) are used in this study. The SST anomalies are constructed using a combination of observed data along with models and historical sampling grids. This global database has a horizontal resolution of $2.5^{\circ}$ by $2.5^{\circ}$. The domain bounded by -22 to $63^{\circ} \mathrm{N}$ and 111 to $15^{\circ} \mathrm{E}$ is considered in order to capture the signal of the most important climate variability modes for the Central American isthmus such as El Niño Southern Oscillation (ENSO), the Pacific Decadal Oscillation (PDO), the Atlantic Multi decadal Oscillation (AMO), the North Atlantic Oscillation (NAO), and the Tropical North Atlantic (TNA), which in turns, have shown to be relevant in terms of variability of rainfall during the season JJA (Fallas-López and Alfaro, 2012a, b). The SST anomalies are used as predictors in the CCA models.

The Niño 3.4 index (Trenberth, 1997) provided by the International Research Institute for Climate and Society (IRI, 2015) is used to estimate the relationship between this index 
Table 1. Geographical position of the gauge stations in degrees north for latitude and degrees west for longitude.

\begin{tabular}{|c|c|c|c|c|c|}
\hline Station & LAT & LON & Country & Region & $\begin{array}{l}\text { Num. of years } \\
\text { without MSD }\end{array}$ \\
\hline La Argentina & 10.03 & 84.35 & Costa Rica & Pacific & 3 \\
\hline Fabio Baudrit & 10.00 & 84.43 & Costa Rica & Pacific & 2 \\
\hline Juan Santa Maria & 10.00 & 84.17 & Costa Rica & Pacific & 3 \\
\hline Liberia & 10.58 & 85.58 & Costa Rica & Pacific & 9 \\
\hline Nicoya & 10.15 & 85.45 & Costa Rica & Pacific & 5 \\
\hline Santa Cruz & 10.17 & 85.25 & Costa Rica & Pacific & 8 \\
\hline Bagaces & 10.53 & 85.25 & Costa Rica & Pacific & 18 \\
\hline CIGEFI & 9.94 & 84.04 & Costa Rica & Pacific & 21 \\
\hline Bluefields & 12.02 & 83.78 & Nicaragua & Caribbean & 19 \\
\hline Ocotal & 13.62 & 86.47 & Nicaragua & Pacific & 6 \\
\hline Chinandega & 12.63 & 87.13 & Nicaragua & Pacific & 9 \\
\hline Juigalpa & 12.10 & 85.37 & Nicaragua & Pacific & 7 \\
\hline Managua & 12.14 & 86.16 & Nicaragua & Pacific & 5 \\
\hline Puerto Cabezas & 14.05 & 83.38 & Nicaragua & Caribbean & 9 \\
\hline Rivas & 11.44 & 85.83 & Panama & Pacific & 13 \\
\hline David & 8.40 & 82.43 & Panama & Pacific & 8 \\
\hline Los Santos & 7.42 & 80.42 & Panama & Pacific & 5 \\
\hline San Miguel & 13.43 & 88.15 & El Salvador & Pacific & 3 \\
\hline Asuncion Mita & 14.33 & 89.71 & Guatemala & Pacific & 11 \\
\hline Huehuetenango & 15.32 & 91.50 & Guatemala & Pacific & 4 \\
\hline LaborOvalle & 14.87 & 91.48 & Guatemala & Pacific & 12 \\
\hline La Fragua & 14.96 & 89.58 & Guatemala & Pacific & 13 \\
\hline Amapala & 13.29 & 87.65 & Honduras & Pacific & 18 \\
\hline Choluteca & 13.32 & 87.15 & Honduras & Pacific & 9 \\
\hline Tegucigalpa & 14.06 & 87.22 & Honduras & Pacific & 9 \\
\hline
\end{tabular}
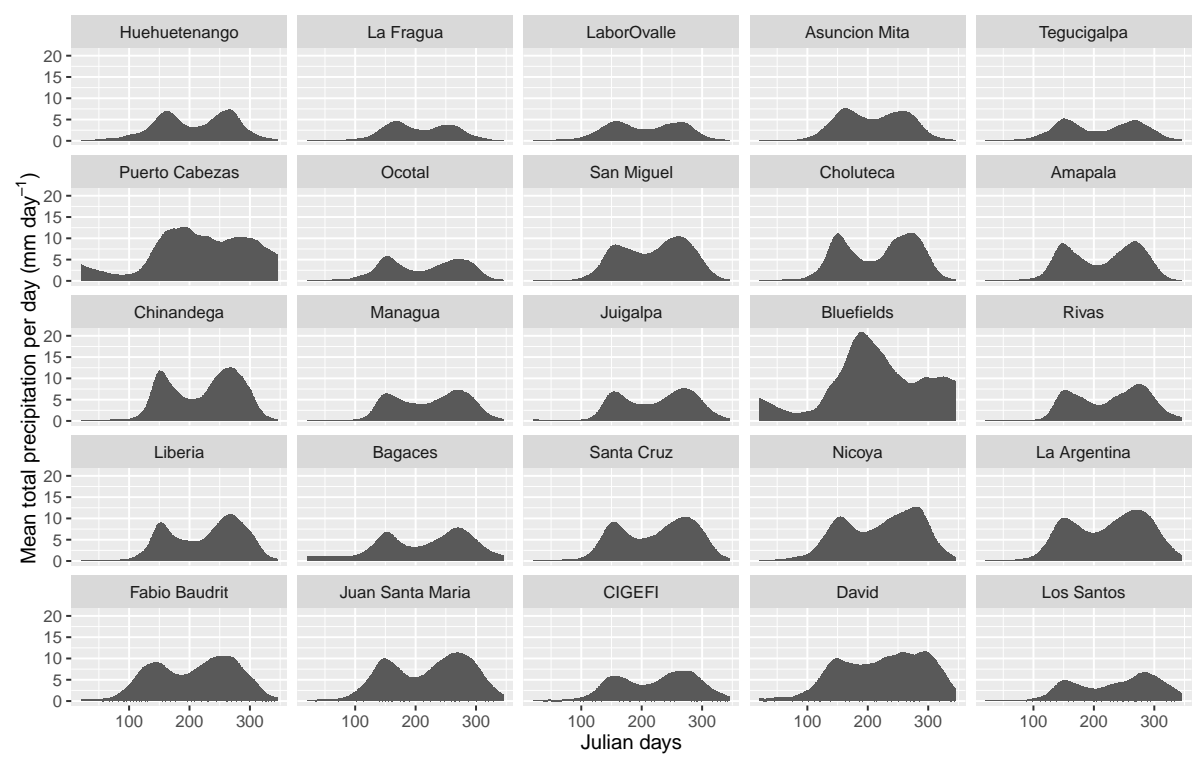

Figure 2. Annual cycle of precipitation in every station for the period 1961-2012.

and relevant features of the MSD by means of empirical contingency tables for conditional data.

Horizontal wind data at $925 \mathrm{hPa}$ is provided by the NCEP/NCAR reanalysis (Kalnay et al., 1996; Kistler et al.,
2001) which has a horizontal resolution of $2.5^{\circ}$ by $2.5^{\circ}$. The wind data is used to calculate the CLLJ index as in Amador (2008) and Maldonado et al. (2016). 


\section{Methods}

Based on the methodology developed in Alfaro (2014), and also applied by Solano (2015), the daily precipitation times series are filtered using a running triangular weight average with a window of 31 days, to avoid or minimise interruptions of the MSD due to weakening of the trades and/or approaching of the ITCZ, as suggested by Ramírez (1983) and Alfaro (2014). An algorithm to systematically identify the features of the MSD is applied to the filtered daily precipitation time series. Figure 3 shows the schematics of this approach. This algorithm seeks for the timing of each phase of the MSD (start, minimum, and end), besides the intensity and magnitude of the MSD. Notice that this algorithm provides an annual value of each quantity, which are used as indexes to characterise the MSD later in this study. The start of the MSD is considered as the moment when the decrease in precipitation initiates, usually after May-June. The end of the MSD is when the precipitation stops increasing, normally taking place around September-October. The minimum occurs in between the start and end of the MSD. The MSD intensity is defined as the minimum rainfall detected during the MSD (or the depth of the valley in Fig. 3), meanwhile the magnitude is the total precipitation divided by the total number of days between the start and end of the MSD. The description of the whole MSD detecting process is explained as follows: first, the algorithm scans for the precipitation minimum in the filtered time series within a reasonable range of days for the existence of the MSD, determined by the climatologies of each station, i.e. typically from 1 June to 30 August. If the precipitation minimum falls outside this period, it is not considered a MSD event. Second, the nearest inflection points to the minimum are sought to determine the start and the end of the MSD. The shortest distance allowed between the inflection points and the minimum is 5 days. Consequently, the shortest MSD would have a duration of 10 days. Moreover, the inflection points have the restriction that the difference of precipitation between them and the minimum should be at least $20 \%$ per day. It is worth mentioning, that not all the years present the inflection points and the minimum. For the scope of this study, the years missing any of the MSD phases are removed. The causes for those fails in the detection of the MSD phases are several, however, they can be attributed to anomalous years with a extended dry season at the beginning of the year, combined with an earlier and severe MSD, or anomalous drier condition during the secondary precipitation maximum, years with no MSD at all, and in most cases due to missing data in the observations. In Table 1 the number of years without MSD is shown per station. A statistical summary of the features of the MSD is shown in Fig. 4.

The contingency tables method seeks for a significant predictive relationship between two variables, being one independent and the other dependent (Alfaro, 2007; Fallas-López and Alfaro, 2012a). The time series are divided into three categories: below normal, normal and above normal (BN, N,

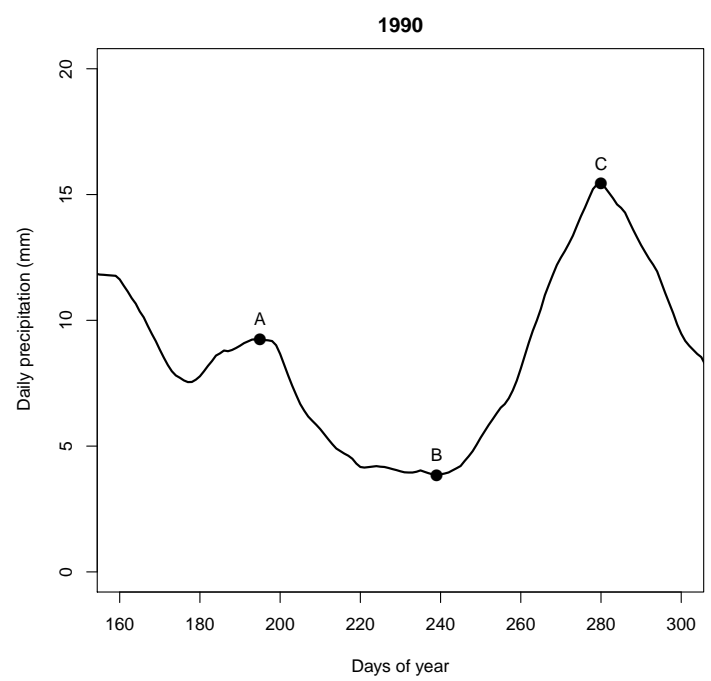

Figure 3. Filtered daily time series for the observed precipitation in station La Argentina during 1990. The dots represent the beginning (A), minimum (B) and end (C) of the MSD. In this year the MSD started by day 195 (14 July), reached the minimum at day 239 (27 August) and ended by day 280 (7 October).

AN, respectively) using the percentiles 33rd and 67th. FallasLópez and Alfaro (2012a) have shown that using these categories provides a good measure of the possible states of El Niño and the MSD indexes, besides, the information obtained is easy to use for the public. Thus, the contingency tables are estimated for conditional events to study the dependence of the MSD features (intensity and magnitude) with ENSO events (independent variable). As mentioned above, the years in which the algorithm does not detect any of the phases or no MSD at all, are dismissed. The statistical significance is estimated by means of bootstrapping with no replace (Gershunov and Barnett, 1998). With bootstrapping, a synthetic time series normally distributed is generated from random noise, then, we estimated contingency tables for the artificial time series. This process is repeated several times to obtain a number of random frequencies normally distributed, which in this case is 1000 repetitions, thus, we obtain 1000 contingency tables per station. If the value of the observed absolute frequency is greater than the 90th of the synthetic frequencies, then the observation is significant at 0.1 significance level. The same can be said for the 0.05 and 0.01 of significance level.

As a tool to investigate the variability of the MSD, we use Canonical correlation analysis (CCA, Wilks, 2011) which is a statistical technique that searches for pairs of patterns in two multivariate data sets (fields), and constructs sets of transformed data variables by projecting the original data onto those patterns. These new variables maximise the interrelationships between the two fields. The new variables can be used, analogously to the regression coefficient in the multiple regression. The new variables or vector weights are 


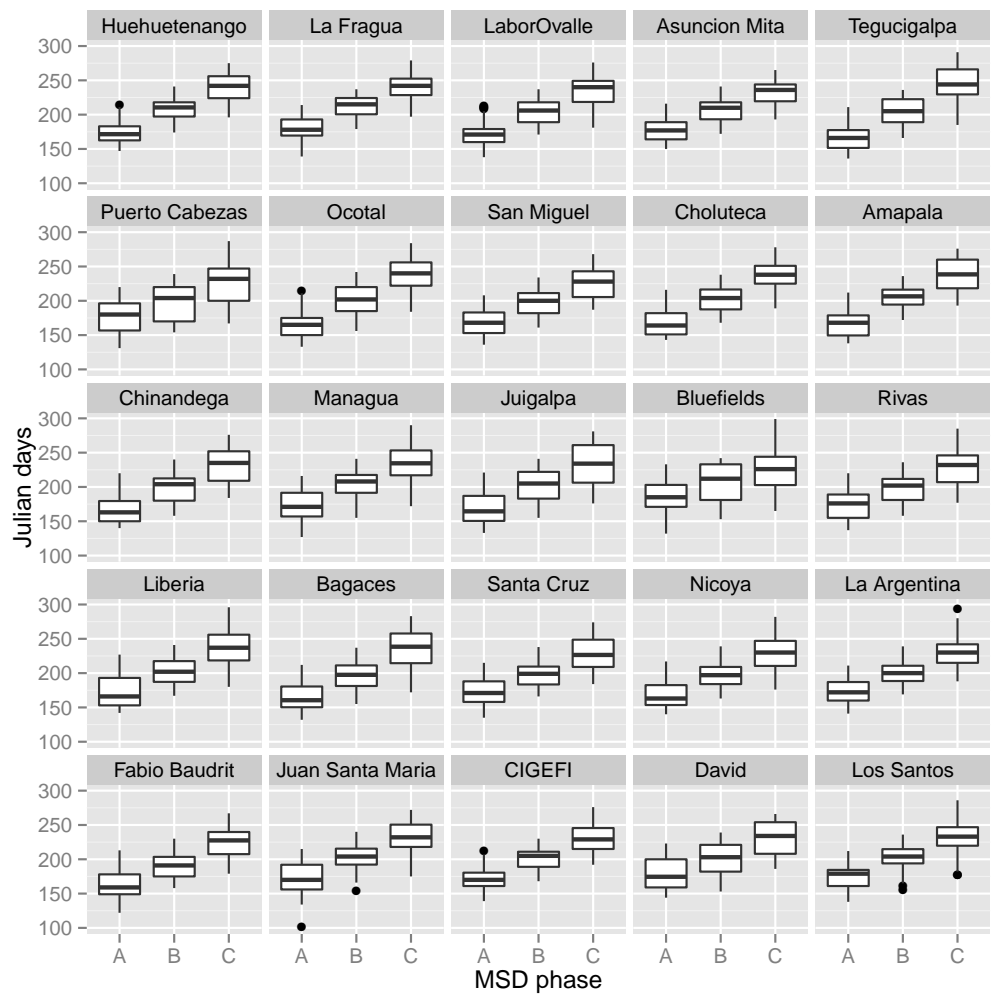

Figure 4. Box-plot of the indexes describing the MSD timing. In the $x$ axis are each of the events defining the MSD, start (A), minimum (B), and end (C). In the $y$ axis are the time-coordinates in Julian days. The upper and lower limits of each box correspond to the first and third quartiles (the 25th and 75th percentiles). The upper (lower) whisker extends from the hinge to the highest (lowest) value that is within 1.5 times inter-quartile range of the hinge. Data beyond the end of the whiskers are outliers and plotted as dots. The median is the bold line in each box. Note that the panels are distributed from north to south, left to right and top to bottom.

also known as canonical vectors, and their projection with their respective fields as canonical variates. CCA can be useful in different applications, such as: (i) to obtain diagnostic aspects of the coupled variability of two fields, in the case when the time series of observations of the two fields are simultaneous, or (ii) to perform statistical forecasts, in the case when the time series of observations of one field precede the other (e.g. Alfaro, 2007; Maldonado and Alfaro, 2011; Fallas-López and Alfaro, 2012b; Maldonado et al., 2013).

In this study CCA is used as a diagnostic tool, however, models for statistical forecasting can be built for future use. Consequently, CCA is employed in order to analyse the relationship between the SSTs monthly anomalies (SSTA, also denoted field $\boldsymbol{X}$ ) with each of the indexes (start, minimum, end, intensity and magnitude of MSD) estimated to represent each of the features of the MSD (each index would be the field $\boldsymbol{Y}$, for the corresponding model), that is, we seek for a statistical relationship between the large and regional scale features of the SSTA and the characteristics of the MSD in each of the stations (local scale). The above CCA methodology is based on Maldonado et al. (2013) and it is implemented as follows: the fields (SSTA, MSD indexes) are first reduced by means of principal component analy- sis (PCA) to assure stability in the CCA parameters. A maximum of 17 EOFs and CCA modes in the filtering stage are allowed. This threshold was suggested by Gershunov and Cayan (2003) and Alfaro (2007) to avoid overparameterisation. The optimal combination of EOFs and CCA modes are calculated by means of the goodness index $\left(R^{2}\right)$. Notice that any set EOFs will produce unique CCA modes for that specific set, then, once the best combination of EOFs is determined, that set EOF is capturing the maximum variability in each field ( $\boldsymbol{X}$ and $\boldsymbol{Y}$ ), separately, for each specific CCA model (intensity and magnitude). The maximum possible number of CCA modes, however, is determined first by the minimum number of EOFs between both fields. Then with the goodness skill, the maximum number of CCA modes is found for the best fit to avoid any overparameterisation in the model $\hat{\boldsymbol{Y}}=\boldsymbol{b}^{T} \cdot \boldsymbol{X}$, where the elements of $\boldsymbol{b}$ are the ordinary least-squares regression coefficients computed with $\mathrm{CCA}$, and $\hat{\boldsymbol{Y}}$ is the predicted value of $\boldsymbol{Y}$. The $R^{2}$ is computed using cross-validation models with 1-month window from 1961-2012 for each station in all the models. This metric also allows identifying the best month to predict any of the MSD features. It is worth mentioning that at the end the models would not necessarily have $17 \mathrm{EOF}$ and CCA modes. 
Stations having indexes with more than $30 \%$ of missing data (i.e. fails detecting MSD events) are discarded. In total, 21 stations are left for the CCA models. Precipitation data are transformed to a normal distribution using percentiles, to achieve better performance in the EOF. The 21 stations having less than $30 \%$ of missing data are filled using the longterm means of each index. Note that filling the data in this step is not the same procedure described above.

\section{Results}

\subsection{General features of the MSD}

Figure 4 shows a statistical summary of the timing of the MSD phases. Each phase exhibits subtle differences throughout the stations. Those discrepancies suggest to study this phenomenon separately per station. For example, from Fig. 4, one can see that in the southern part of Central America (Panama, Costa Rica, Nicaragua) the MSD tends to start, develop and end earlier than in the northern part (El Salvador, Guatemala, Honduras), in agreement with previous studies such as Alfaro (2002) and Herrera et al. (2015). In the southern stations, typically, the start of the MSD is detected by 20 June, the minimum is reached by 19 July and the end by 20 August, meanwhile at the north the start is observed by 22 June, the minimum by 24 July and the end around 24 August. Note that the difference can be up to 20 days in each phase from south to north if the stations are analysed separately. The results in Fig. 4 also show the high temporal and spatial variability existent throughout the region agreement with Alfaro (2002) and Amador (2008), but that feature is also observed at local scales as noted by Ramírez (1983); Hernández and Fernández (2015); Alfaro (2014), and Solano (2015).

The algorithm captures similar MSD structure in stations located over the eastern Nicaragua (Bluefields and Puerto Cabezas) at the Caribbean region. In addition, the stations located at the Caribbean coast present later development of the MSD, starting in average by 29 June, the minimum in 21 July, and the end at 14 August, therefore, being later and shorter in the Caribbean than in the Pacific side of Central America, showing a marked difference between the eastern and western Central America. This MSD structure over the Caribbean has been previously studied by Martin and Schumacher (2011), which concluded that the MSD in the Caribbean is controlled by different external forcing than the one operating in the Pacific sector.

This observed latitudinal difference in the timing in each MSD phase is examined using a $t$ test (not shown). The results, nevertheless, show no statistical difference among the stations at $90 \%$ of significance level, except for the start index in Bluefields station, indicating that in the Caribbean slope the MSD is out-of-phase at least at the start. Thus, it can be argued that the MSD over the Pacific occur simultaneously as found by Magaña et al. (1999).
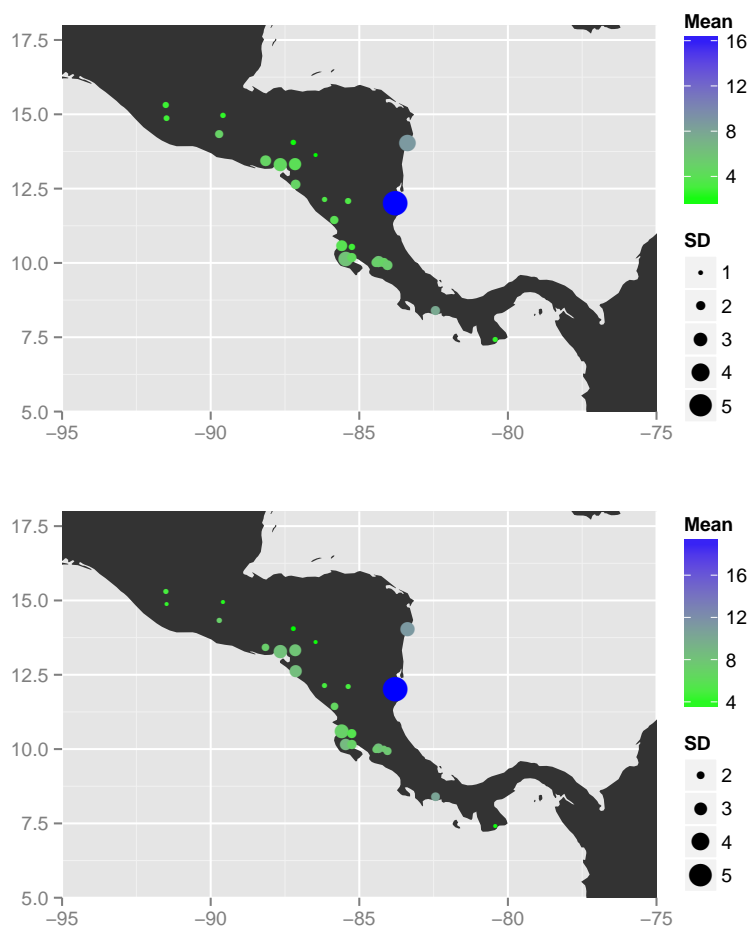

Figure 5. Mean and standard deviation for the MSD intensity (mm, top) and magnitude (mm day ${ }^{-1}$, bottom) for the period 1961-2012. Note the color scale is not the same in both figures, since the intensity and magnitude are not necessarily of the same order of magnitude. The dots size represents the standard deviation.

The intensity and magnitude of the MSD also show high spatial variability (Fig. 5), with a strong contrast between the Pacific and the Caribbean coasts. The Pacific side presents drier MSDs than in the Caribbean basin. In the western Central America, the mean intensity is $4.06 \mathrm{~mm}$ $(\sigma=1.85 \mathrm{~mm})$ and mean magnitude of $6.50 \mathrm{~mm} \mathrm{day}^{-1}$ $\left(\sigma=2.00 \mathrm{~mm} \mathrm{day}^{-1}\right)$, with the highest score detected in David, Panama with an intensity of $7.70 \mathrm{~mm}(\sigma=2.01 \mathrm{~mm})$, and a magnitude of $10.45 \mathrm{~mm}\left(\sigma=2.20 \mathrm{~mm}\right.$ day $\left.^{-1}\right)$. On the Caribbean side, Bluefields and Puerto Cabezas show the highest records in intensity and magnitude. The mean intensity recorded in Bluefields is $16.64 \mathrm{~mm}(\sigma=5.50 \mathrm{~mm})$, and Puerto Cabezas $8.81 \mathrm{~mm}(\sigma=3.68 \mathrm{~mm})$, whereas the mean magnitude scored is $19.93 \mathrm{~mm}_{\text {day }^{-1}}\left(\sigma=5.39 \mathrm{~mm} \mathrm{day}^{-1}\right)$ and $11.31 \mathrm{~mm} \mathrm{day}^{-1}\left(\sigma=3.30 \mathrm{~mm} \mathrm{day}^{-1}\right)$. As above, using $t$ test is determined that the differences in the MSD intensity and magnitude indexes amongst the stations are statistically significant at $90 \%$ of significance level.

Inter-annual variability of the MSD intensity and magnitude is examined in Fig. 6. Correlations with Niño 3.4 index are shown in Fig. 6a, c. Notice that all the stations show a significant negative correlation, except one (San Miguel, El Salvador), nevertheless in both cases the correlation is relatively low ( 0.24 for intensity and 0.18 for magnitude), hence, this result can be discarded. Tables 2 and 3 show a summary 


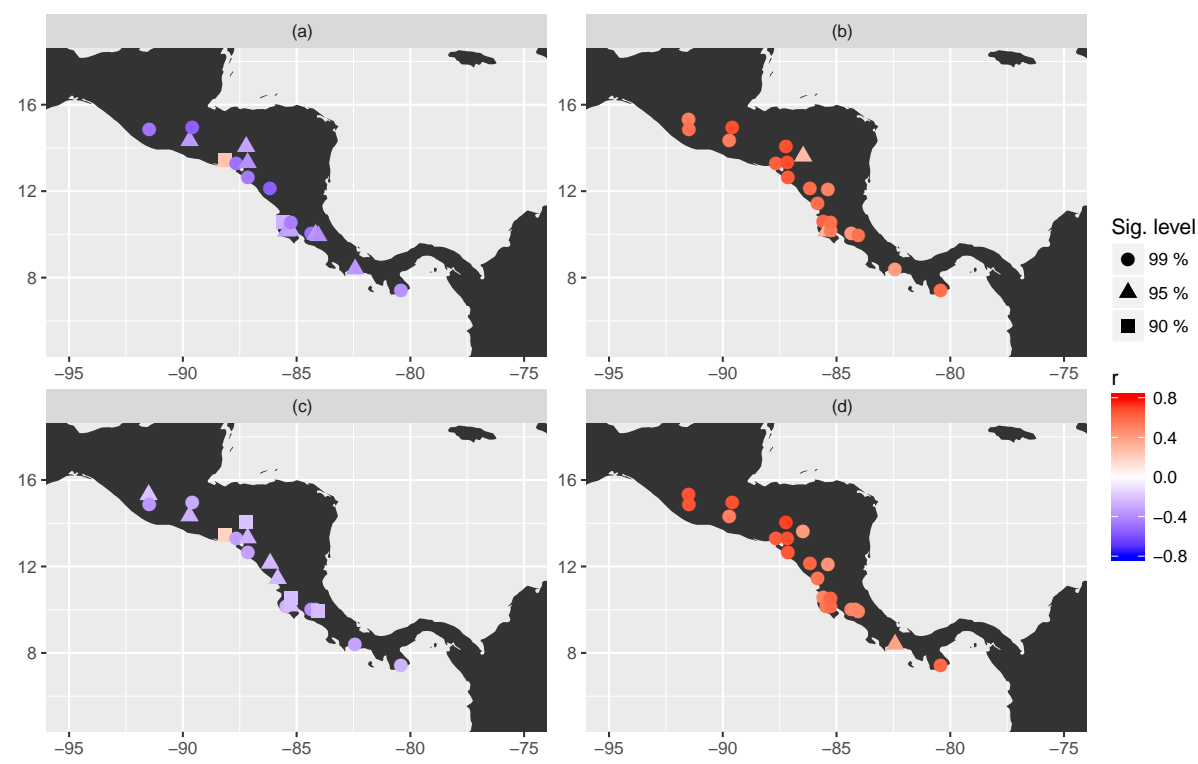

Figure 6. Top Pearson correlation between MSD intensity and (a) CLLJ index and (b) Niño 3.4 indexes. Bottom the same metric but for the MSD magnitude with (c) CLLJ and (d) Niño 3.4 indexes. Niño 3.4 index is taken for June. The CLLJ index is estimated from the daily time series, using the definition by Amador (2008) for July.

of the contingency tables calculated. In both cases, the extreme values of the MSD intensity and magnitude present a connection with ENSO events, however, those conditions are not observed in all the stations, despite some of them have a significant correlation with Niño 3.4 (e.g. Liberia and Juigalpa). Notice that the results for the Caribbean stations are not statistically significant. Alfaro (2014) and Solano (2015) have found similar results for stations in Costa Rica; and Fallas-López and Alfaro (2012a) reported the same relationship with other stations in Central America. This association between the SST anomalies in the Niño 3.4 region and the MSD intensity and magnitude over the west cost of Central America can be connected with low-level wind anomalies over the Caribbean Sea. Previous studies have found a relationship between the fluctuation of the CLLJ and precipitation during the summer months (Wang, 2007; Amador, 2008). Figure $6 \mathrm{~b}, \mathrm{~d}$ show the correlation of the intensity and magnitude of the MSD with the CLLJ index. Similarly, most of the stations show positive significant correlations, except the stations in the Caribbean. It is known that in the summer months (JJA) during warm (cold) ENSO episodes the CLLJ is stronger (weaker) than normal (Amador, 2008) with a correlation of -0.53 ( $p$ value $<0.01$ ). Hidalgo et al. (2015) also noted that during stronger (weaker) CLLJ the ITCZ is located south (north) from the normal position, leading to a reduction (increase) in the total precipitation during boreal summer (JJA), thus, affecting the MSD. Therefore, the bottom line of this result is that the ENSO events modulate the intensity and magnitude of the MSD. It is worth to mention again that from these results, the ENSO events explain only the inter-annual variability of the MSD in the Pacific coast.
The same estimations were done for the other variables (start, minimum, end), however, the results do not shown significant correlations with El Niño and CLLJ index (not shown).

\subsection{Canonical correlation analysis}

Models based on CCA are tailored for each of the indexes describing the features of the MSD, defined in Sect. 3. Using the SST anomalies as predictor ( $X$ field), CCA identifies SST patterns that are related to the perturbations of the MSD features ( $Y$ field, predictant). The goodness index $\left(R^{2}\right)$ is shown in Fig. 7. The intensity and magnitude show the best skill score compared to the other indexes. These results show that the models to study the timing of the MSD phases have a poor performance using the CCA technique. Consequently, those models are not considered in the further analysis. Both CCA models for MSD intensity and magnitude show one of the highest values of $R^{2}$ in April, which means in operational terms, information concerning the MSD intensity and magnitude can be retrieve up to 3 months in advance of an event. This would be valuable for preparation and planning of the societal, economical and agricultural activities during the MSD period. Notice that both models also shown the highest results in July, concurrently with the existence of the MSD, and the CLLJ.

In this study, we analyse the SSTA patterns identified by the model in June, since for that month, CCA models show a relative high $R^{2}$, and there is also a 1-month leading time for forecasting the MSD. Besides, the SST do not change significantly from June to July, when the CCA models have the best performance, thus, the SST in July is expected to be close to 
Table 2. Summary of contingency tables for each station. The tables were estimated using Niño 3.4 index and the mean intensity per year. The categories were defined using the 33rd (below normal, BN) and 67th (above normal, AN). Years in which the algorithm failed detecting any of the phases of the MSD, were removed. The star $\left(^{*}\right)$ represents cases in which the observed condition in column 2 or 3 dominates, and has statistical significance $>90 \%$.

\begin{tabular}{|c|c|c|c|c|}
\hline Station & $\begin{array}{l}\text { SST AN and } \\
\text { Intensity BN }\end{array}$ & $\begin{array}{l}\text { SST BN and } \\
\text { Intensity AN }\end{array}$ & $r$ (Kendall) & $p$ value \\
\hline La Argentina & $*$ & $*$ & -0.38 & 0.00 \\
\hline Fabio Baudrit & & & -0.05 & 0.62 \\
\hline Juan Santa Maria & $*$ & $*$ & -0.34 & 0.00 \\
\hline Liberia & & & -0.21 & 0.05 \\
\hline Nicoya & & $*$ & -0.24 & 0.02 \\
\hline Santa Cruz & $*$ & $*$ & -0.26 & 0.01 \\
\hline Bagaces & & $*$ & -0.30 & 0.01 \\
\hline CIGEFI & & $*$ & -0.30 & 0.02 \\
\hline Bluefields & & & -0.04 & 0.77 \\
\hline Ocotal & $*$ & & -0.27 & 0.01 \\
\hline Chinandega & $*$ & & -0.33 & 0.00 \\
\hline Juigalpa & & & -0.21 & 0.04 \\
\hline Managua & $*$ & $*$ & -0.39 & 0.00 \\
\hline Puerto Cabezas & & & -0.02 & 0.87 \\
\hline Rivas & & & -0.13 & 0.26 \\
\hline David & $*$ & $*$ & -0.32 & 0.00 \\
\hline Los Santos & & $*$ & -0.22 & 0.03 \\
\hline San Miguel & & & 0.25 & 0.01 \\
\hline Asuncion Mita & & & -0.22 & 0.04 \\
\hline Huehuetenango & $*$ & & -0.14 & 0.16 \\
\hline Labor Ovalle & $*$ & & -0.35 & 0.00 \\
\hline La Fragua & $*$ & $*$ & -0.42 & 0.00 \\
\hline Amapala & & $*$ & -0.40 & 0.00 \\
\hline Choluteca & $*$ & & -0.28 & 0.01 \\
\hline Tegucigalpa & $*$ & $*$ & -0.26 & 0.02 \\
\hline
\end{tabular}

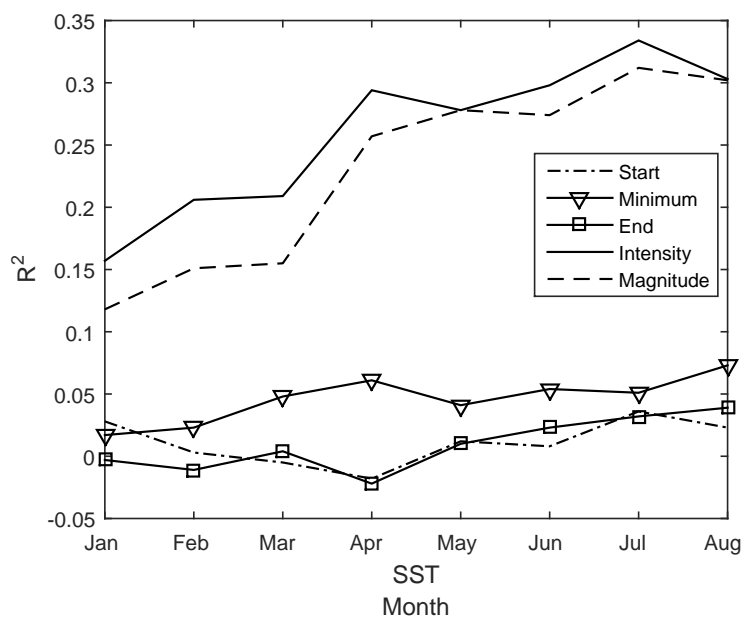

Figure 7. Goodness index $\left(R^{2}\right)$ estimated as the average of the Pearson correlation between synthetic time series generated by crossvalidation models and the observed MSD features per station.

the SST in June. The best combination of EOF and CCA modes for the MSD intensity are $X=14, Y=4$ EOFs and
2 CCA modes, and for the MSD magnitude $X=11, Y=6$ EOFs and 3 CCA modes, meaning that for each model (for intensity and magnitude respectively) the best fit is achieved when using 2 and 3 modes (canonical variates) respectively, capturing the maximum influence of the SST on the precipitation field, and specifically in the modulation of the MSD. Figure 8 shows the Pearson correlation between the predicted time series generated using cross-validation models and the observations of both intensity and magnitude in each station. Each case, the station exhibits relative high significant correlation, about 0.35 in average.

The $X$ loadings (correlation between the canonical vectors of the SST and the SSTA) of the first mode controlling the MSD intensity shows a bipolar pattern in the correlation with the SSTAs surrounding Central America (Fig. 9a, b). The highest positive correlations are found over the Pacific in the El Niño region, whereas the highest negative correlation are found over the Tropical North Atlantic and near to the Brazil coast. The influence of this variability mode on the precipitation in Central America has been previously studied by Enfield and Alfaro (1999); Maldonado and Alfaro (2011) and Maldonado et al. (2013), but for the secondary 
Table 3. Same as Table 2 but for MSD magnitude.

\begin{tabular}{lccrr}
\hline Station & $\begin{array}{c}\text { SST AN and } \\
\text { Magnitude BN }\end{array}$ & $\begin{array}{c}\text { SST BN and } \\
\text { Magnitude AN }\end{array}$ & $r$ (Kendall) & $p$ value \\
\hline La Argentina & $*$ & & -0.38 & 0.00 \\
Fabio Baudrit & & & -0.04 & 0.71 \\
Juan Santa Maria & $*$ & $*$ & -0.36 & 0.00 \\
Liberia & $*$ & & -0.17 & 0.10 \\
Nicoya & $*$ & & -0.26 & 0.01 \\
Santa Cruz & $*$ & $*$ & -0.23 & 0.03 \\
Bagaces & & $*$ & -0.23 & 0.06 \\
CIGEFI & & & -0.23 & 0.07 \\
Bluefields & & & -0.06 & 0.66 \\
Ocotal & $*$ & & -0.06 & 0.55 \\
Chinandega & & $*$ & -0.32 & 0.00 \\
Juigalpa & & & -0.08 & 0.43 \\
Managua & & & -0.25 & 0.01 \\
Puerto Cabezas & & $*$ & 0.02 & 0.87 \\
Rivas & & & -0.24 & 0.03 \\
David & $*$ & & -0.32 & 0.00 \\
Los Santos & $*$ & & -0.26 & 0.01 \\
San Miguel & $*$ & & 0.19 & 0.06 \\
Asuncion Mita & $*$ & & -0.28 & 0.01 \\
Huehuetenango & $*$ & & -0.21 & 0.01 \\
Labor Ovalle & $*$ & & -0.35 & 0.00 \\
La Fragua & $*$ & & -0.29 & 0.01 \\
Amapala & & & 0.01 \\
Choluteca & & & 0.05 \\
Tegucigalpa & & & & \\
\hline
\end{tabular}

Table 4. Correlations between $X$ mode times series and Oceanic El Niño Index (ONI, NOAA, 2016), El Niño Modoki Index (EMI, JAMSTEC, 2016), Pacific Decadal Oscillation (PDO, NOAA, 2016), Tropical North Atlantic (TNA, NOAA, 2016), and Atlantic Multidecadal Oscillation (AMO, NOAA, 2016). The differences ONI-TNA and ONI-AMO are calculated with the normalized indexes. Correlations are marked with * and ** for 0.05 and 0.01 of significance level respectively.

\begin{tabular}{lcccccccc}
\hline Variable & Mode & ONI & EMI & PDO & TNA & AMO & ONI-TNA & ONI-AMO \\
\hline Intensity & 1 & $0.55^{* *}$ & 0.07 & -0.12 & $-0.62^{* *}$ & 0.18 & $0.82^{* *}$ & $0.56^{* *}$ \\
& 2 & $-0.42^{* *}$ & 0.00 & 0.16 & $-0.55^{* *}$ & $0.52^{* *}$ & 0.09 & $-0.41^{* *}$ \\
\hline Magnitude & 1 & $0.70^{* *}$ & 0.11 & -0.01 & $-0.45^{* *}$ & 0.21 & $0.81^{* *}$ & $0.71^{* *}$ \\
& 2 & -0.02 & 0.03 & $0.39^{*}$ & -0.17 & 0.26 & 0.10 & -0.02 \\
& 3 & $-0.33^{*}$ & 0.15 & $-0.38^{* *}$ & $-0.66^{* *}$ & 0.11 & 0.23 & $-0.32^{*}$ \\
\hline
\end{tabular}

peak of precipitation during August-October (ASO), thus, this results shows that the rainfall during the MSD is governed by the same variability mode present during the highest precipitation season in Central America. On the other hand, for the MSD magnitude, the first mode exerts more influence of the SSTA over the El Niño region, and the regional waters close the west Mexican coast. Notice that in both cases also high positive correlations are found near the western coast of Mexico revealing that both models are affected by the influence of regional waters, varying with the same phase that the superficial temperatures in the El Niño region. The $Y$ loadings in both models are negatively correlated with most of the stations (Fig. 9c, d). That means for a state in which the water over the Pacific is warmer (colder) than normal, plus the SST over the Atlantic colder (warmer) than normal, the intensity and magnitude of the MSD drier (wetter). This results also connects the MSD period with the second rainfall peak, that is, SSTs conditions for drier MSDs, would persist leading to less rainfall during the second peak, following the results in Maldonado et al. (2013). The temporal scores (canonical variates) of this mode in both models show that this mode has mainly inter-annual variations (Fig. 9e, f).

The $X$ loadings of the second mode are shown in Fig. 10a and b. The MSD intensity is dominated by nega- 


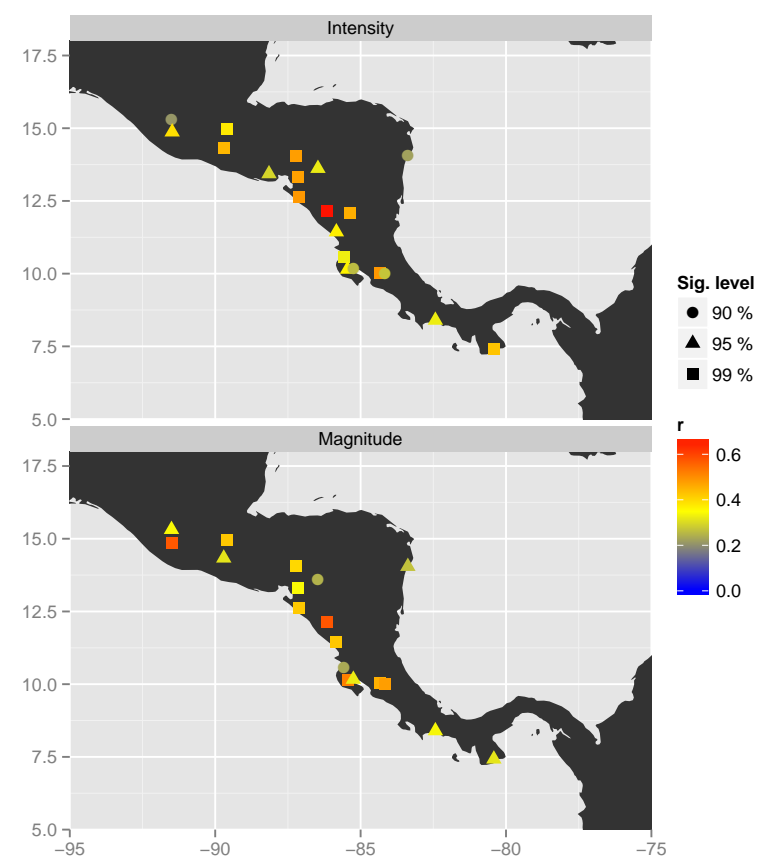

Figure 8. Pearson correlation of the CCA models with the time series of intensity (top) and magnitude (bottom) of MSD.

tive correlations with SST anomalies in the Tropical North Atlantic, the Caribbean and Gulf of Mexico and the eastern Pacific, being more important than the first region. The $X$ loadings for the MSD magnitude on the other hand, reveal a tripolar configuration in the North Pacific. This tripolar setting is located in the region where the PDO develops. The PDO has shown more influence in the southern USA and northern Mexico than in Central America (Muñoz et al., 2010; Maldonado et al., 2016), and that could be the reason that its influence is observed in the second mode. The $Y$ loadings in both cases (Fig. 10c, d) show a non-uniform distribution of the correlation. For the MSD intensity (Fig. 10c), the stations are positively correlated with this mode, meanwhile, the MSD magnitude (Fig. 10d) shows a clear division between northern and southern Central America, being the former region (Guatemala, El Salvador, Honduras and west Nicaragua) negatively correlated and the latter region (Costa Rica, Panama and east Nicaragua) positively correlated. The temporal scores for the intensity model exhibit mainly interannual variability with a negative trend after 1990 (Fig. 10e), while the temporal scores of the magnitude (Fig. 10f) present a decadal variation, that again possibly relates to the influence of the PDO.

The MSD magnitude is the only feature with a third mode, the $X$ loadings (Fig. 11a) reveal that this mode is dominated by regional SSTs in the Pacific and Tropical North Atlantic. The north and south Pacific show a dipole being positive and negative correlations respectively. The $Y$ loadings (Fig. 11b) show a north/south division being positively correlated to the north and negatively to the south, while the temporal scores (Fig. 11c) reveal an interannual variation of this mode.

Table 4 shows the correlation between the SST modes for each CCA model and the indexes associated to the maximum correlation found using CCA. The results from this table confirm our previous observations, while the first order modes in the intensity and magnitude can be mainly driven by El Niño 3.4 and Tropical North Atlantic, the combination of these indexes, and even with low frequency events such as the AMO turn to be more important. Higher order modes of the magnitude show an important association with PDO which is also a low frequency event.

\section{Discussion and conclusions}

The MSD is characterised using daily time series of rainfall for 25 stations located mainly in the Pacific coast of Central America during the 1961-2012 period. An algorithm to detect the MSD phases is developed in order to compare the timing of the MSD start, date of minimum, and end in each station. This algorithm clearly captures the development of the MSD over the Pacific, but also a similar MSD-like structure in two stations located in the Caribbean coast. The results confirm previous observations showing the high spatial and temporal variability of the MSD, thus, suggesting the need of a more detailed analysis. We, thus, analyse the features of the MSD individually per station, using a combination of empirical analysis (contingency tables) and a more sophisticated statistical method as the canonical correlation analysis to diagnose the variability of the MSD in terms of changes in the SSTA of the surrounding waters.

The MSD intensity and magnitude are correlated with the Niño 3.4 and the CLLJ index in stations located over the western side of Central America. These results reveal a significant negative correlation in almost all the stations with ENSO phases, i.e. warm (cold) anomalies in the Niño 3.4 region, corresponding to an enhanced (decreased) CLLJ intensity, are associated with drier (wetter) MSD. The results of the correlation with the CLLJ show also a positive association of such process, indicating that with a stronger (weaker) jet the MSD intensifies (decreases). However, other processes such the migration of the ITCZ, the North American Monsoon and perturbations in the SLP fields over the Amazon could also be engaged with anomalous MSD (Hidalgo et al., 2015). The two stations placed in the Caribbean side do not reveal results statistically significant, hence, suggesting that other elements are involved explaining the annual rainfall variability during their MSD period.

The outputs of CCA show that the MSD intensity is mainly modulated by a bipolar configuration in the SST anomalies formed between the Pacific and the Tropical North Atlantic and Caribbean sea, meanwhile, the first mode controlling the MSD magnitude shows more influence from El Niño and the regional waters close to the western coast of Mexico and Central America. This variability mode in both models has 


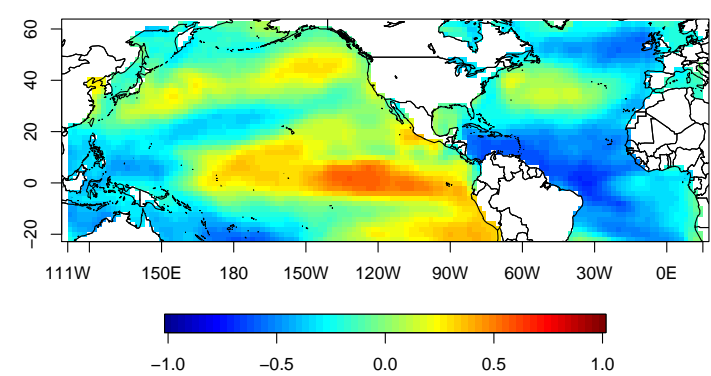

(a)

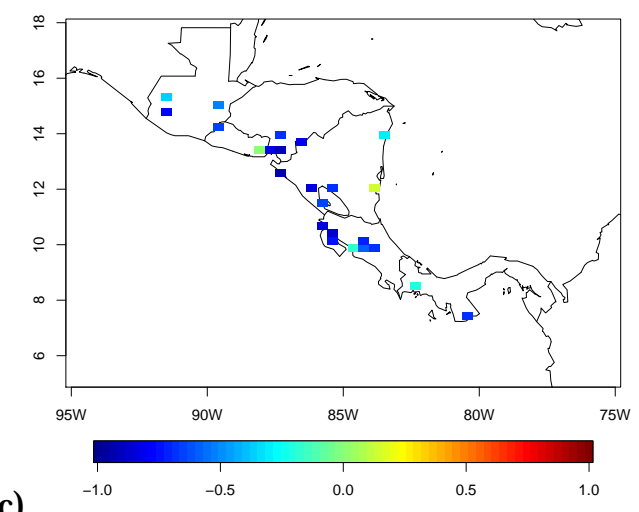

(c)

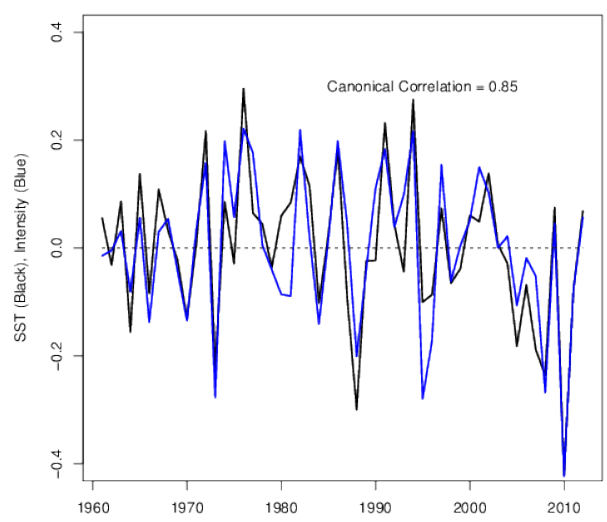

(e)

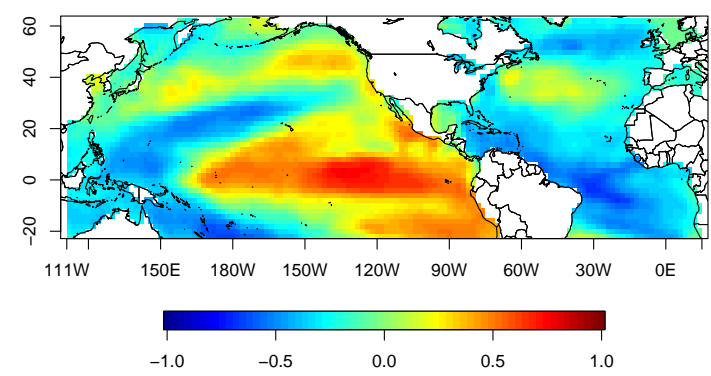

(b)

(d)
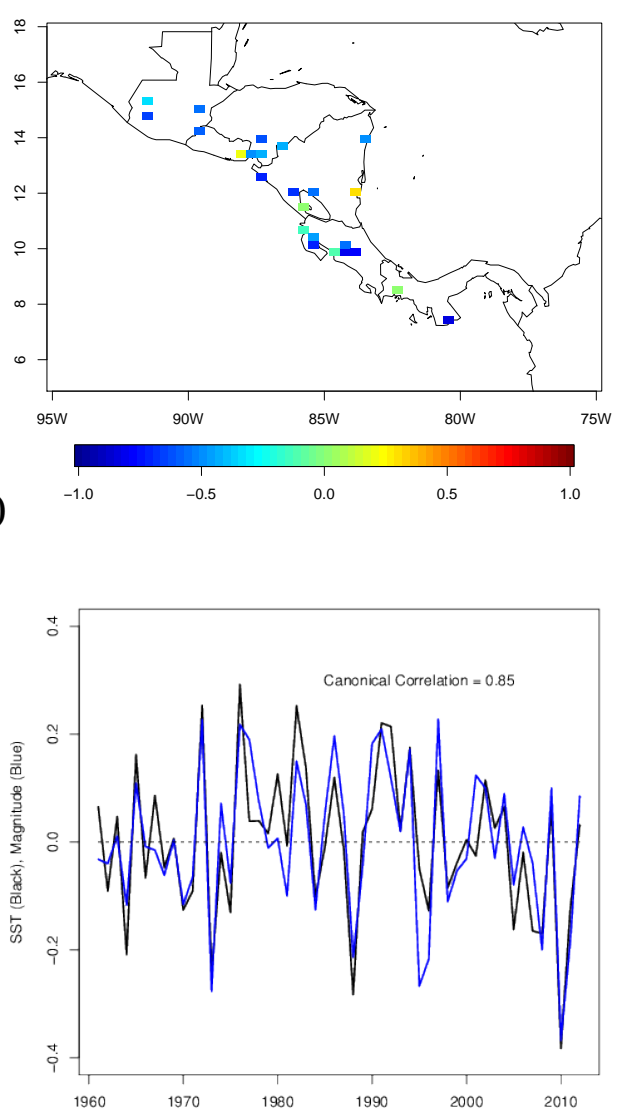

(f)

Figure 9. CCA mode 1 for both MSD intensity and magnitude. In the left column are the $X$ (upper) and $Y$ (middle) loadings, and the time scores (bottom) for the intensity. In the right column the same but for the magnitude.

an inter-annual scale, with negative effects in precipitation, i.e. when this mode is positive for both intensity and magnitude, a reduction in rainfall is observed in almost all the stations. Similar SST dipole has been reported to influence the anomalies in rainfall during the months of the highest precipitation events (August-November), and it has been associated with intensification/reduction of the trades, leading to a decrease/increase of precipitation in Central America during the second rainfall period (Alfaro, 2007; Maldonado et al., 2013), however, these results show this mode is present prior to the quarter ASO and is also modulating the precipitation during boreal summer.

The second mode in both models presents more complex structures, and it is difficult to distinguish a general pattern affecting the intensity as well as magnitude of the MSD. For the intensity model, the SST show a negative correlation pattern over the equatorial Pacific and North Atlantic waters, nevertheless, the latter region dominates; the time series for this mode show a negative trend after 1990. Meanwhile, for the magnitude, a tripolar configuration over the vicinity of 


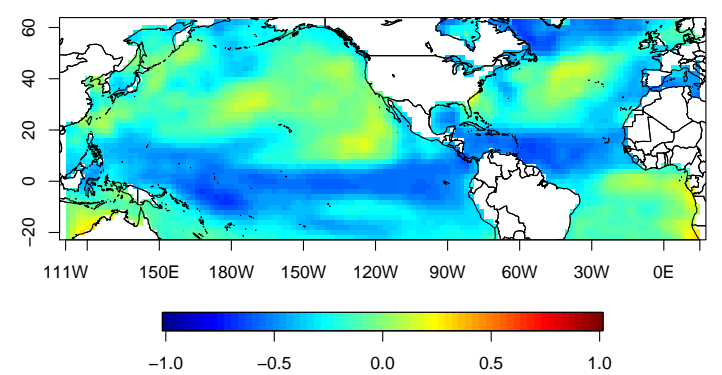

(a)

(c)
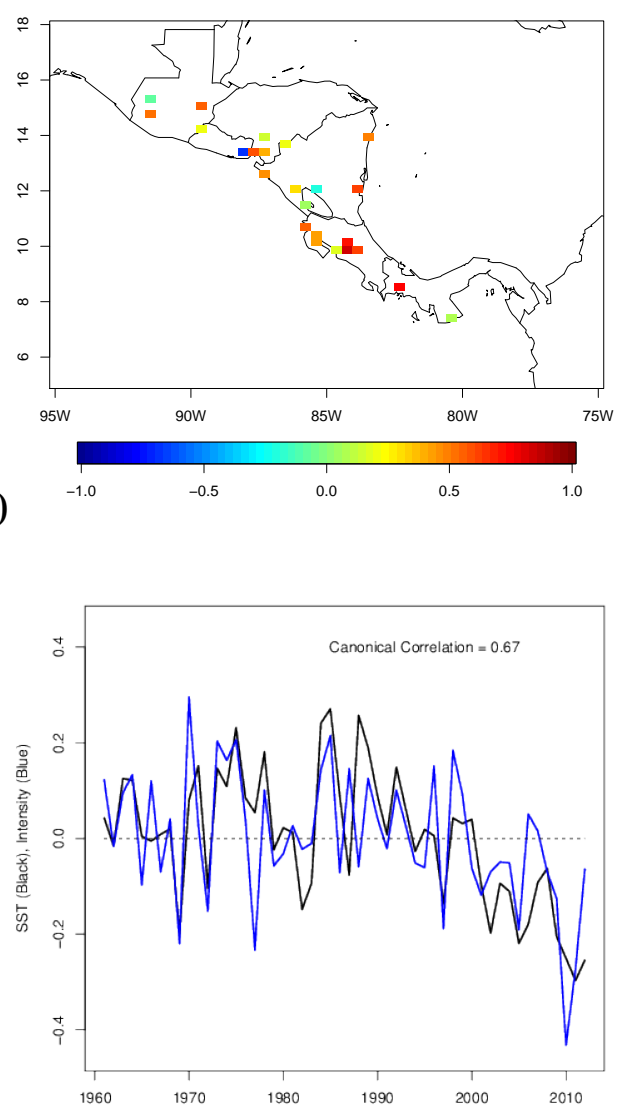

(e)

Figure 10. Same as Fig. 9 but for Mode 2.

the PDO development region is found. Also negative correlations are found over the Gulf of Mexico. The influence of the PDO should be taken with caution and needs more analysis since the PDO has shown more influence in the southern USA and northern Mexico than in Central America. The time series exhibited inter-decadal variability. As previously mentioned, the correlations between both variables (intensity and magnitude) and this mode, however, do not depict a clear pattern in the stations; for the MSD intensity the correlations reveal a positive association with the SSTA, meanwhile, for the MSD magnitude shows a division be-

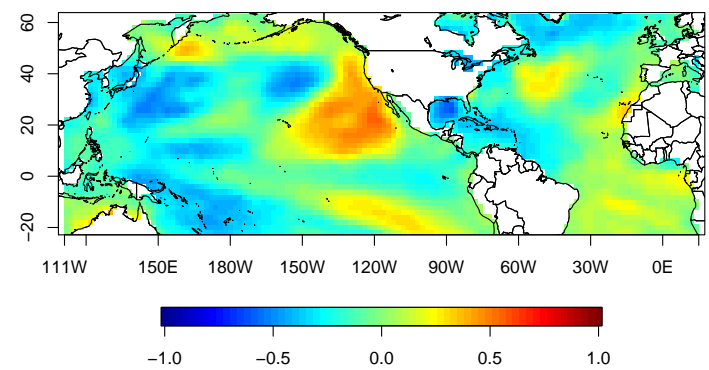

(b)
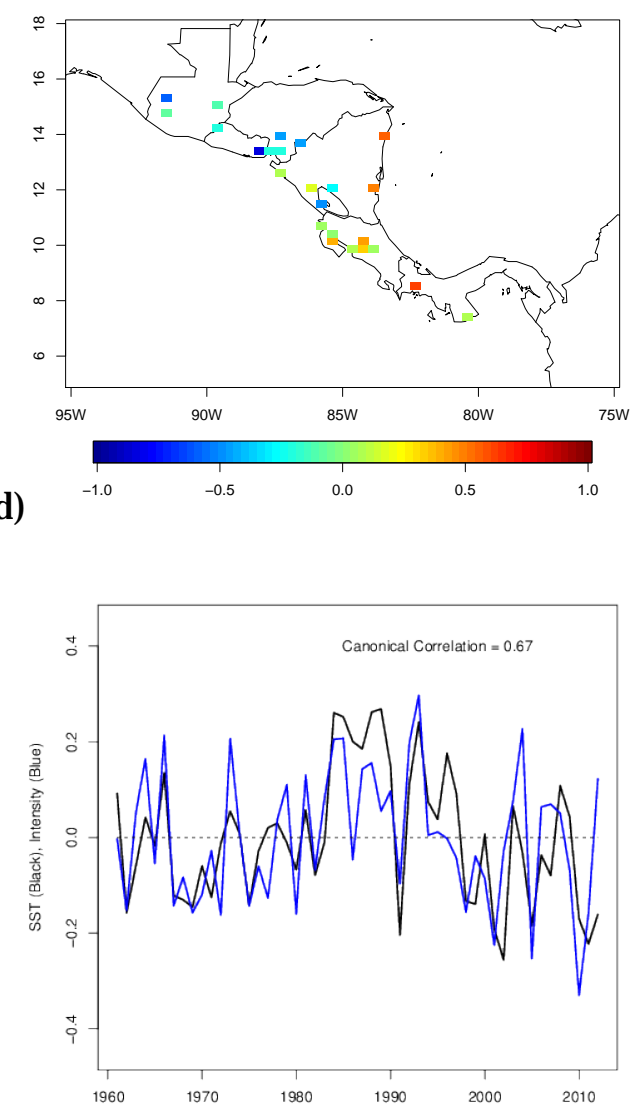

(f)

tween the north and south Central America, being the north (Guatemala, Honduras, El Salvador and west Nicaragua) affected negatively and the south and Caribbean (Costa Rica, Panama and east Nicaragua) positively. It is clear that the second mode is not controlling the precipitation in both models in the same way. The North Atlantic waters become more important for the MSD intensity, hence, could be associated with the same controlling mechanism present during the first precipitation maximum (Alfaro, 2007; Fallas-López and Alfaro, 2012b). While for the MSD magnitude the tripolar configuration might suggest the influence of the PDO, also noted 


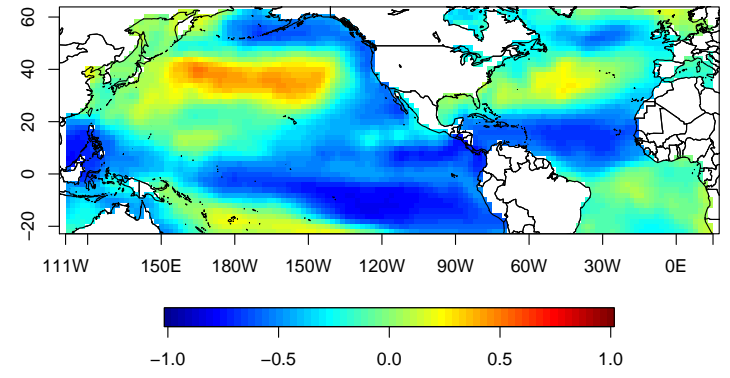

(a)

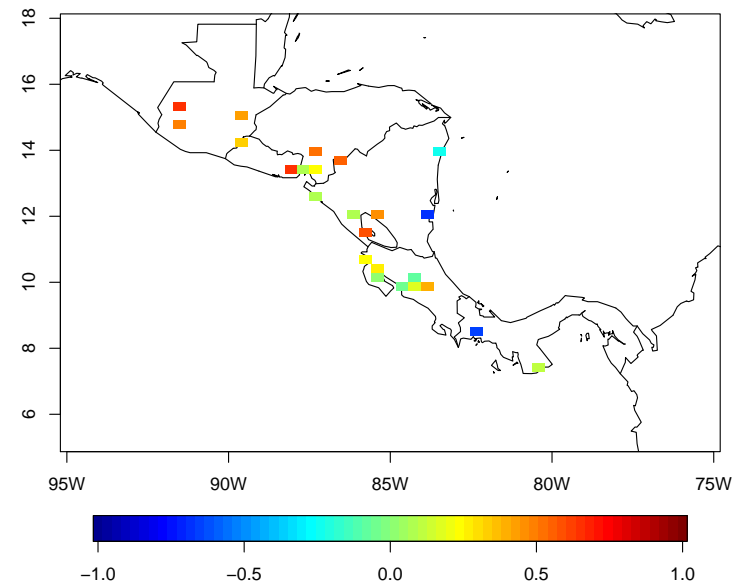

(b)

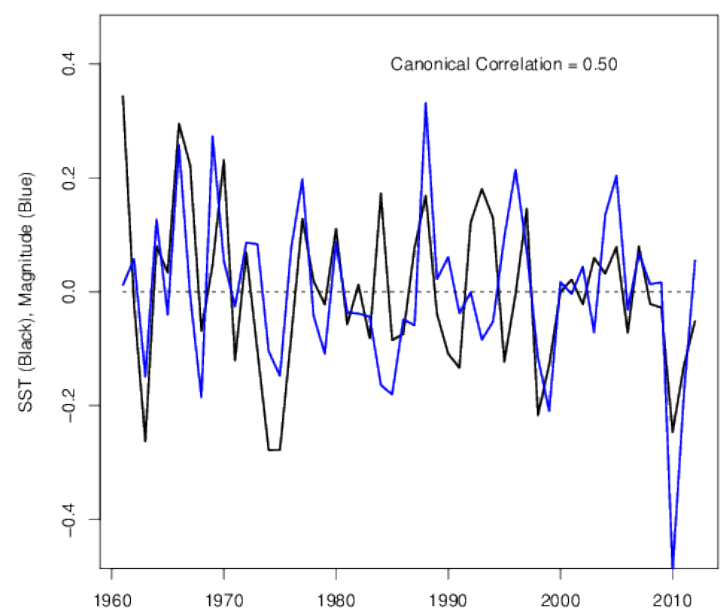

(c)

Figure 11. CCA mode 3 for MSD magnitude. $X$ (a) and $Y$ (b) loadings, and (c) the time scores.

in the contrasting effects of this mode between north and south Central America.

The MSD magnitude is the only variable with higher CCA modes. The third mode reveals the influence of regional wa- ters close to the Central America Pacific and a dipole formed between the north (positive) and south (negative) Pacific, affecting with opposite sign the eastern (negative) and western (positive) part of Central America. This mode presents an inter-annual variability scale. The CCA allows identifying patterns of the SST affecting variables describing the MSD such as the intensity and magnitude, however, it shows a poor performance related to the temporal variables. Another benefit achieved using CCA was the identification of particular months suitable for prediction of the intensity and magnitude of the MSD, being capable of forecasting up to 3 months in advance, which is a reasonable time in terms of practical matters related to prevention and planning for the season. Finally, it is worth pointing out that this analysis also provide a systematic method to study the MSD features, that can be used for statistical forecasts of such phenomenon in an operative context also.

\section{Data availability}

Niño 3.4 index is available at http://iridl.ldeo.columbia. edu/SOURCES/.Indices/.nino/.NCEP/.NINO34/.

PDO, TNA, and AMO indexes are available at http://www.esrl.noaa.gov/psd/data/climateindices/list/, and EMI index is available at http://www.jamstec.go.jp/ frcgc/research/d1/iod/enmodoki_home_s.html.en.

Acknowledgements. This research was carried out within the CNDS research school, supported by the Swedish International Development Cooperation Agency (Sida) through their contract with the International Science Programme (ISP) at Uppsala University (contract number: 54100006). The authors would like to thank the Centre for Natural Disaster Science (CNDS) in Uppsala University, the National Centers for Environmental Prediction (NCEP), and the National Center for Atmospheric Research (NCAR) for the reanalysis data. We would also like to acknowledge support via project VI-805-A9-532, CIGEFI-UCR, provided via a SIDA-CSUCA agreement and project 805-B6-143, supported by UCR, CONICIT and MICITT.

Edited by: J. D. Pabón-Caicedo

Reviewed by: A. E. Guhl Corpas and one anonymous referee

\section{References}

Alfaro, E.: Some Characteristics of the Annual Precipitation Cycle in Central America and their Relationships with its Surrounding Tropical Oceans, Tópicos Meteorológicos y Oceanográficos, 9, 1-13, https://www.imn.ac.cr/documents/10179/20907/T\%C3\% B3picos+Meteorol\%C3\%B3gicos+y+Oceanogr\%C3\%A1ficos+ -+2000-2, 2002.

Alfaro, E.: Uso del análisis de correlación canónica para la predicción de la precipitación pluvial en Centroamérica, Ingeniería y Competitividad, 9, 33-48, http://bibliotecadigital.univalle.edu. co/xmlui/handle/10893/1622, 2007. 
Alfaro, E.: Caracterización del "veranillo" en dos cuencas de la vertiente del Pacífico de Costa Rica, América Central (Characterization of the Mid Summer Drought in two Pacific slope river basins of Costa Rica, Central America), International Journal of Tropical Biology, 62, 1-15, available at: https://www.academia.edu/9493294 (last access: 22 April 2016), 2014.

Alfaro, E. and Soley, J.: Descripción de dos métodos de rellenado de datos ausentes en series de tiempo meteorológicas, Revista de Matemáticas: Teoría y Aplicaciones, 16, 59-74, available at: http://dx.doi.org/10.15517/rmta.v16i1.1419 (last access 22 April 2016), 2009.

Amador, J. A.: A Climatic Feature of the Tropical Americas: The Trade Wind Easterly Jet, Tópicos Meteorológi$\cos$ y Oceanográficos., 5, 91-102, available at: https: //www.imn.ac.cr/documents/10179/20907/T\%C3\%B3picos+ Meteorol\%C3\%B3gicos+y+Oceanogr\%C3\%A1ficos+-+1998-2 (last access: 22 April 2016), 1998.

Amador, J. A.: The Intra-Americas Sea Low-level Jet Overview and Future Research, Ann. NY Acad. Sci., 1146, 153-188, doi:10.1196/annals.1446.012, 2008.

Amador, J. A., Alfaro, E. J., Lizano, O. G., and Magaña, V. O.: Atmospheric forcing of the eastern tropical Pacific: A review, Prog. Oceanogr., 69, 101-142, doi:10.1016/j.pocean.2006.03.007, 2006.

Ashby, S. A., Taylor, M. A., and Chen, A. A.: Statistical models for predicting rainfall in the Caribbean, Theor. Appl. Climatol., 82, 65-80, doi:10.1007/s00704-004-0118-8, 2005.

Chen, A. A. and Taylor, M. A.: Investigating the link between early season Caribbean rainfall and the El Niño+ 1 year, Int. J. Climatol., 22, 87-106, doi:10.1002/joc.711, 2002.

Chinchilla-Ramírez, G.: Resumen Meteorológico Julio 2014, Boletín Meteorológico Mensual, https://www.imn.ac.cr/documents/ 10179/14639/JULIO (last access: 22 April 2016), 2014.

Enfield, D. B. and Alfaro, E. J.: The Dependence of Caribbean Rainfall on the Interaction of the Tropical Atlantic and Pacific Oceans, J. Climate, 12, 2093-2103, doi:10.1175/15200442(1999)012<2093:TDOCRO>2.0.CO;2, 1999.

Fallas-López, B. and Alfaro, E. J.: Uso de herramientas estadísticas para la predicción estacional del campo de precipitación en América Central como apoyo a los Foros Climáticos Regionales. 1: Análisis de tablas de contingencia, Revista de Climatología, 12, 61-79, http://webs.ono.com/reclim7/reclim12e.pdf, 2012a.

Fallas-López, B. and Alfaro, E. J.: Uso de herramientas estadísticas para la predicción estacional del campo de precipitación en América Central como apoyo a los Foros Climáticos Regionales, 2: Análisis de Correlación Canónica, Revista de Climatología, 12, 93-105, http://webs.ono.com/reclim8/reclim12g.pdf, 2012b.

Gershunov, A. and Barnett, T.: ENSO influence on intraseasonal extreme rainfall and temperature frequencies in the contiguous United States: Observations and model results, J. Climate, 11, 1575-1586, doi:10.1175/15200442(1998)011<1575:EIOIER>2.0.CO;2, 1998.

Gershunov, A. and Cayan, D. R.: Heavy Daily Precipitation Frequency over the Contiguous United States: Sources of Climatic Variability and Seasonal Predictability, J. Climate, 16, 2752-2765, doi:10.1175/15200442(2003)016<2752:HDPFOT>2.0.CO;2, 2003.
Hernández, K. and Fernández, W.: Estudio de la evaporación para el cálculo del inicio y la conclusión de la época seca y lluviosa en Costa Rica, Tópicos Meteorológicos y Oceanográficos, 14, 18-26, 2015.

Herrera, E., Magaña, V., and Caetano, E.: Air-sea interactions and dynamical processes associated with the midsummer drought, Int. J. Climatol., 35, 1569-1578, doi:10.1002/joc.4077, 2015.

Hidalgo, H. G., Durán-Quesada, A. M., Amador, J. A., and Alfaro, E. J.: The Caribbean Low-Level Jet, the Inter-Tropical Convergence Zone and Precipitation Patterns in the Intra-Americas Sea: A Proposed Dynamical Mechanism, Geogr. Ann. A, 97, 41-59, doi:10.1111/geoa.12085, 2015.

International Research Institute for Climate and Society IRI, Earth Institute, Columbia University: NCEP NINO34 from Indices nino, New York, USA, Dataset: http://iridl.ldeo.columbia.edu/ SOURCES/.Indices/.nino/.NCEP/.NINO34/, 2015.

Japan Agency for Marine-Earth Science and Technology (JAMSTEC): Modoki ENSO, Japan, Dataset: http://www.jamstec.go. jp/frcgc/research/d1/iod/enmodoki_home_s.html.en, 2016.

Kalnay, E., Kanamitsu, M., Kistler, R., Collins, W., Deaven, D., Gandin, L., Iredell, M., Saha, S., White, G., Woollen, J., Zhu, Y., Leetmaa, A., Reynolds, R., Chelliah, M., Ebisuzaki, W., Higgins, W., Janowiak, J., Mo, K. C., Ropelewski, C., Wang, J., Jenne, R., and Joseph, D.: The NCEP/NCAR 40-Year Reanalysis Project, B. Am. Meteorol. Soc., 77, 437-471, doi:10.1175/15200477(1996)077<0437:TNYRP>2.0.CO;2, 1996.

Karnauskas, K. B., Seager, R., Giannini, A., and Busalacchi, A. J.: A simple mechanism for the climatological midsummer drought along the Pacific coast of Central America, Atmósfera, 26, 261281, doi:10.1016/S0187-6236(13)71075-0, 2013.

Kistler, R., Collins, W., Saha, S., White, G., Woollen, J., Kalnay, E., Chelliah, M., Ebisuzaki, W., Kanamitsu, M., Kousky, V., van den Dool, H., Jenne, R., and Fiorino, M.: The NCEP-NCAR 50-Year Reanalysis: Monthly Means CD-ROM and Documentation, B. Am. Meteorol. Soc., 82, 247-267, doi:10.1175/15200477(2001)082<0247:TNNYRM>2.3.CO;2, 2001.

Magaña, V., Amador, J. A., and Medina, S.: The Midsummer Drought over Mexico and Central America, J. Climate, 12, 1577-1588, doi:10.1175/15200442(1999)012<1577:TMDOMA>2.0.CO;2, 1999.

Maldonado, T. and Alfaro, E.: Predicción estacional para ASO de eventos extremos y días con precipitación sobre las vertientes Pacífico y Caribe de América Central, utilizando análisis de correlación canónica, InterSedes, 12, 78-108, http://www. intersedes.ucr.ac.cr/ojs/index.php/intersedes/article/view/301, 2011.

Maldonado, T., Alfaro, E., Fallas-López, B., and Alvarado, L.: Seasonal prediction of extreme precipitation events and frequency of rainy days over Costa Rica, Central America, using Canonical Correlation Analysis, Adv. Geosci., 33, 41-52, doi:10.5194/adgeo-33-41-2013, 2013.

Maldonado, T., Rutgersson, A., Amador, J., Alfaro, E., and Claremar, B.: Variability of the Caribbean low-level jet during boreal winter: large-scale forcings, International J. Climatol., 36, 1954 1969, doi:10.1002/joc.4472, 2016.

Martin, E. R. and Schumacher, C.: The Caribbean Low-Level Jet and Its Relationship with Precipitation in IPCC AR4 Models, J. Climate, 24, 5935-5950, doi:10.1175/JCLI-D-11-00134.1, 2011. 
Muñoz, E., Busalacchi, A. J., Nigam, S., and Ruiz-Barradas, A.: Winter and Summer Structure of the Caribbean Low-Level Jet, J. Climate, 21, 1260-1276, doi:10.1175/2007JCLI1855.1, 2008.

Muñoz, E., Wang, C., and Enfield, D.: The Intra-Americas Sea springtime surface temperature anomaly dipole as fingerprint of remote influence, J. Climate, 23, 43-56, doi:10.1175/2009JCLI3006.1, 2010.

National Oceanic and Atmospheric Administration (NOAA): Earth System Research Laboratory, Physical Science Division, Boulder, Colorado, Datasets: http://www.esrl.noaa.gov/psd/data/ climateindices/list/, 2016.

Ramírez, P.: Estudio Meteorológico de los Veranillos en Costa Rica, Nota de investigación 5, Instituto Meteorológico Nacional, Ministerio de Agricultura y Ganadería, San José, Costa Rica, 1983.

Smith, T., Reynolds, R., Peterson, T. C., and Lawrimore, J.: Improvements to NOAA's Historical Merged Land-Ocean Surface Temperature Analysis (1880-2006), J. Climate, 21, 2283-2296, 2007.

Solano, E.: Análisis del comportamiento de los períodos caniculares en Costa Rica en algunas cuencas del Pacífico Norte y del Valle Central entre los años 1981 y 2010, Tesis de Grado, Licenciatura, Escuela de Física, Universidad de Costa Rica, San José, Costa Rica, 2015.

Spence, J. M., Taylor, M. A., and Chen, A. A.: The effect of concurrent sea-surface temperature anomalies in the tropical Pacific and Atlantic on Caribbean rainfall, Int. J. Climatol., 24, 1531-1541, doi:10.1002/joc.1068, 2004.

Taylor, M. A. and Alfaro, E. J.: Climate of Central America and the Caribbean, in: Encyclopedia of World Climatology, edited by: Oliver, J. E., Springer, the Netherlands, 183-186, 2005.

Taylor, M. A., Enfield, D. B., and Chen, A. A.: Influence of the tropical Atlantic versus the tropical Pacific on Caribbean rainfall, J. Geophys. Res.-Oceans, 107, 10-1-10-14, doi:10.1029/2001JC001097, 2002.
Trenberth, K. E.: The Definition of El Niño, B. Am. Meteorol. Soc., 78, 2771-2777, doi:10.1175/15200477(1997)078<2771:TDOENO>2.0.CO;2, 1997.

Vera, C., Higgins, W., Amador, J., Ambrizzi, T., Garreaud, R., Gochis, D., Gutzler, D., Lettenmaier, D., Marengo, J., and Mechoso, C. R.: Toward a unified view of the American monsoon systems, J. Climate, 19, 4977-5000, http://journals.ametsoc.org/ doi/pdf/10.1175/JCLI3896.1, 2006.

Wang, C.: Variability of the Caribbean Low-Level Jet and its relations to climate, Clim. Dynam., 29, 411-422, doi:10.1007/s00382-007-0243-z, 2007.

Wang, C. and Enfield, D. B.: The Tropical Western Hemisphere Warm Pool, Geophys. Res. Lett., 28, 1635-1638, doi:10.1029/2000GL011763, 2001.

Wang, C. and Enfield, D. B.: A Further Study of the Tropical Western Hemisphere Warm Pool, J. Climate, 16, 1476-1493, doi:10.1175/1520-0442(2003)016<1476:AFSOTT>2.0.CO;2, 2003.

Whyte, F. S., Taylor, M. A., Stephenson, T. S., and Campbell, J. D.: Features of the Caribbean low level jet, Int. J. Climatol., 28, 119128, doi:10.1002/joc.1510, 2008.

Wilks, D. S.: Statistical Methods in the Atmospheric Sciences, Academic Press, Amsterdam, the Netherlands, Boston, USA, Volume 100, 3rd edn., 2011.

Xue, Y., Smith, T., and Reynolds, R.: Interdecadal changes of 30yr SST normals during 1871-2000, J. Climate, 16, 1601-1612, doi:10.1175/1520-0442-16.10.1601, 2003. 